
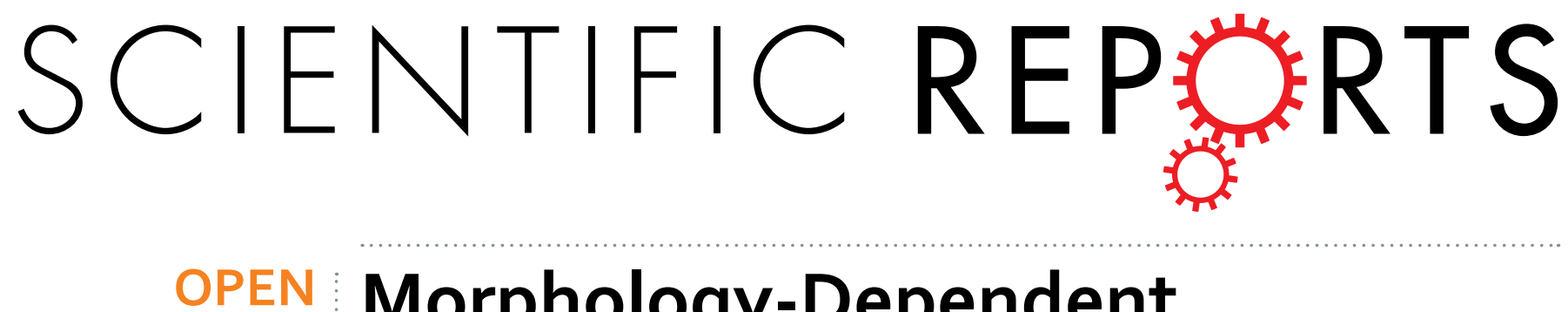

\title{
Morphology-Dependent
}

Electrochemical Performance of Zinc Hexacyanoferrate Cathode for

Received: 31 July 2015

Accepted: 13 November 2015

Published: 16 December 2015

\section{Zinc-Ion Battery}

\author{
Leyuan Zhang, Liang Chen, Xufeng Zhou \& Zhaoping Liu
}

Zinc hexacyanoferrate (ZnHCF) which is a dimorphic (cubic or rhombohedral) Prussian blue analogue and can be intercalated by both monovalent and divalent ions, is a promising cathode material for rechargeable aqueous metal-ion batteries.In this paper, a simple co-precipitation method is developed to tune the particle morphology of $\mathrm{ZnHCF}$ by adjusting the dropping speed at room temperature. Three polyhedral ZnHCF particles, with cubooctahedral, truncated octahedral or octahedral shapes, are obtained at room temperature. Structural transformation from cubic phase of as-prepared ZnHCF to rhombohedral phase is observed by further dehydration of the sample at $70^{\circ} \mathrm{C}$, whereas the dehydrated $\mathrm{ZnHCF}$ crystals still hold the identical polyhedral shape as that of the cubic phase particles. Then the influence of shape and facets on electrochemical performance is studied for polyhedral ZnHCF with rhombohedral structure (RZnHCF). RZnHCF sample with cubooctahedral shape possesses the best rate capability and cyclic stability comparing with RZnHCF particles having truncated octahedral or octahedral shapes. Furthermore, the structure of cuboctahedron RZnHCF particles during electrochemical cycling has been monitored with ex situ X-ray diffraction to demonstrate the reversible zinc-ion intercalation mechanism.

Due to the advantages of low cost, environmental benignness and high ionic conductivity, rechargeable aqueous metal-ion batteries (RAMB) have a giant application potential in large-scale energy storage. "Rocking-chair" RAMB based on monovalent ions $\left(\mathrm{Li}^{+}, \mathrm{Na}^{+}\right.$or $\left.\mathrm{K}^{+}\right)$have been investigated extensively, but most of them show the shortage of low energy density due to the low operating voltage $(<1.5 \mathrm{~V})^{1-15}$. Multivalent metal-ion $\left(\mathrm{Mg}^{2+}, \mathrm{Zn}^{2+}\right.$, $\mathrm{Al}^{3+}$, etc.) RAMB are attracting more and more attention because of their potentially higher energy. But only few systems regarding multivalent ions intercalation chemistry have been reported ${ }^{16-18}$, ascribing to the limits of electrode materials.

In recent years, Prussian blue analogues (PBAs) are widely studied in the energy storage systems as the electrode materials ${ }^{19-23}$. Among PBAs, metal hexacyanoferrates(MeHCFs) with open-framework structures can not only be inserted by monovalent alkaline cations ${ }^{24}$ such as $\mathrm{Li}^{+}, \mathrm{Na}^{+}$or $\mathrm{K}^{+}$, but can also behave as hosts for divalent or trivalent cations ${ }^{25-27}$ including $\mathrm{Mg}^{2+}$ and $\mathrm{Al}^{3+}$. Among the reported RAMB with MeHCFs as electrode materials ${ }^{14,26,28,29}$, most MeHCFs such as CuHCF, NiHCF or CoCuHCF have cubic structure, and the voltages of the batteries are generally lower than $1.5 \mathrm{~V}$ due to the relatively high potential of applicable anode materials. Comparing with most reported anode materials in RAMB, metal zinc shows apparently lower potential of $-0.78 \mathrm{~V}$ vs. standard hydrogen electrode potential. Moreover, the electrical deposition/dissolution of zinc is highly reversible. Therefore, it provides a viable strategy to achieve high operating voltage in RAMB based on zinc ions. But the lack of cathode materials allowing reversible insertion/extraction of divalent $\mathrm{Zn}^{2+}$ in aqueous electrolytes greatly hinders the development of aqueous zinc-ion batteries. To the best of our knowledge, among the known cathode materials only an $\alpha-\mathrm{MnO}_{2}$ cathode material can permit the reversible intercalation of divalent $\mathrm{Zn}^{2+}$ in aqueous electrolytes ${ }^{16}$. Fortunately the structural diversity of MeHCFs makes it possible to design new high-performance divalent metal-ion RAMB, including aqueous zinc-ion battery. Recently, we reported the use of ZnHCF as a novel cathode material in RAMB

Ningbo Institute of Materials Technology and Engineering, Chinese Academy of Sciences, Zhejiang 315201, P.R. China. Correspondence and requests for materials should be addressed to X.Z. (email: zhouxf@nimte.ac.cn) or Z.L. (email: liuzp@nimte.ac.cn) 

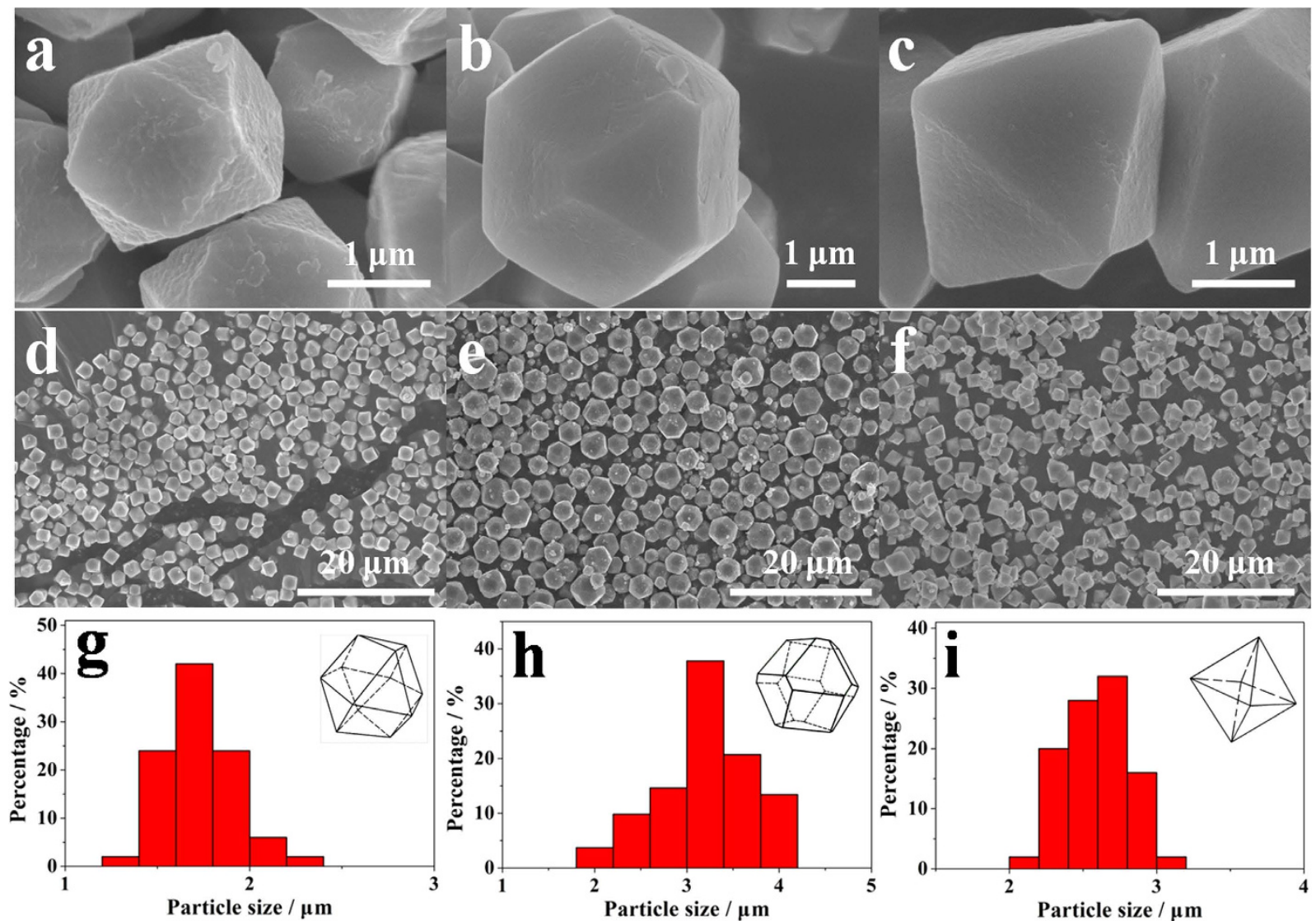

Figure 1. SEM images of (a,d) cuboctahedron ZnHCF, (b,e) truncated octahedron ZnHCF and (c,f) octahedron $\mathrm{ZnHCF}$ obtained at room temperature, and their size distribution histograms (g) for cuboctahedorn $\mathrm{ZnHCF}$ (h) for truncated octahedron ZnHCF and (i) for octahedron ZnHCF, respectively) plotted by counting 50 random particles.

based on zinc ions for the first time ${ }^{30}$. Combining with $\mathrm{Zn}$ as the anode, the $\mathrm{Zn} / \mathrm{ZnHCF}$ system can exhibit a high operating voltage of $1.7 \mathrm{~V}$, giving rise to a high energy density of $100 \mathrm{Wh} \mathrm{kg}^{-1}$.

Compared to most of MeHCFs with cubic structure, $\mathrm{ZnHCF}$ exhibit the rhombohedral structure in which the $\mathrm{ZnN}_{4}$ tetrahedras are linked to $\mathrm{FeC}_{6}$ octahedras via $\mathrm{CN}$ ligands to form a porous three-dimensional framework with large open sites where metal ions such as $\mathrm{Na}^{+}, \mathrm{K}^{+}$and $\mathrm{Cs}^{+}$and water molecules are located. Such a framework endows $\mathrm{ZnHCF}$ s with the possibility of acting as intercalation hosts for various cations. The structural difference between $\mathrm{ZnHCF}$ and common MeHCFs will undoubtedly lead to different intercalation mechanisms of metal ions. The ions intercalation mechanisms in the cubic MeHCFs have been studied intensively ${ }^{12,28-29}$. The feasibility of $\mathrm{ZnHCF}$ as intercalation host for $\mathrm{Na}^{+}$has also been demonstrated by Chio and coworkers ${ }^{23}$. However, the ions intercalation mechanism of divalent metal ions, such as zinc ions in ZnHCF remains to be further studied. This is the first study on the intercalation mechanism for divalent $\mathrm{Zn}^{2+}$ in $\mathrm{ZnHCF}$. Moreover, the effect of the shape and facets of the ZnHCF particles on their electrochemical performance was also systematically investigated in this work. The morphology and crystal-facet-controlled synthesis of cathode materials have recently attracted considerable attention ${ }^{31-33}$ and a number of shape-controlled PBAs can be synthesized ${ }^{34-37}$. For example, Guo's group $^{38}$ found that high-quality Prussian blue crystals in the form of nanocubes showed a better electrochemical performance than low-quality crystals with a granular morphology. By controlling the reaction conditions, uniform ZnHCF particles with a series of regular morphologies were successfully prepared, and their relationship between exposed facets and electrochemical performance was proposed, which will give new insights into the design of high-performance RAMB based on PBAs.

\section{Results}

Shape-controlled Synthesis. In our previous work, the ZnHCF was synthesized by a conventional co-precipitation reaction between $0.1 \mathrm{M} \mathrm{ZnSO}_{4}$ and $0.05 \mathrm{M} \mathrm{K}_{3} \mathrm{Fe}(\mathrm{CN})_{6}$ aqueous solutions and irregular particles were obtained (Fig. S1a) ${ }^{30}$. In this work, by reducing the concentrations of aqueous $\mathrm{ZnSO}_{4}$ and $\mathrm{K}_{3} \mathrm{Fe}(\mathrm{CN})_{6}$ solutions to $0.01 \mathrm{M}$ and adjusting the dropping speed of the reactant solutions, uniform ZnHCF particles with a series of polyhedral shapes can be prepared at room temperature, as shown in Fig. 1. When the aqueous solution of $0.01 \mathrm{M}$ $\mathrm{ZnSO}_{4}$ and aqueous solution of $0.01 \mathrm{M} \mathrm{K}_{3} \mathrm{Fe}(\mathrm{CN})_{6}$ were poured simultaneously into one beaker, ZnHCF particles with cuboctahedron shape were obtained (Fig. 1a). If the reactant solutions were mixed slowly by using dropping pipettes in approx. 20 minutes, the shape of $\mathrm{ZnHCF}$ particles changed to be truncated octahedron (Fig. $1 \mathrm{~b}$ ). If the 


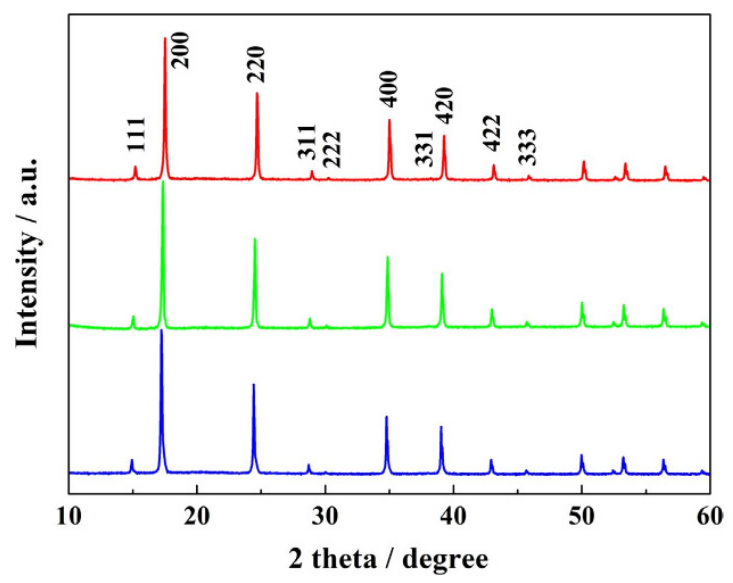

Figure 2. XRD patterns of cubic phase ZnHCF with cubooctahedral (red),truncated octahedral (green) and octahedral (blue) shapes obtained at room temperature.

mixing process of the reactant solutions was further elongated to 2 hours by using peristaltic pump, the shape of ZnHCF crystals became octahedron (Fig. 1c). Figure 1d-f display the overall morphology of shape-controlled ZnHCF particles in a larger domain, which verifies good homogeneity in both shape and size of ZnHCF particles in each sample. The size distribution of $\mathrm{ZnHCF}$ particles is statistically plotted in Fig. 1g-i. The particle sizes of all three samples are distributed within a narrow range of $1-5 \mu \mathrm{m}$. The mean dimension, however, varies slightly between polyhedral particles with different shapes. The cuboctahedron ZnHCF (named as C-ZnHCF hereafter) particles possess the smallest mean size of $\sim 1.7 \mu \mathrm{m}$, and the truncated octahedron ZnHCF (named as T-ZnHCF hereafter) particles have the largest mean size of $\sim 3.2 \mu \mathrm{m}$, whereas the average size of octahedron $\mathrm{ZnHCF}$ (named as $\mathrm{O}-\mathrm{ZnHCF}$ hereafter) lies in between $(\sim 2.6 \mu \mathrm{m})$.

XRD analysis (Fig. 2) of all three morphology-controlled ZnHCF samples dried at room temperature shows identical diffraction patterns of cubic phase $\mathrm{Zn}_{3}\left[\mathrm{Fe}(\mathrm{CN})_{6}\right]_{2} \bullet \mathrm{xH}_{2} \mathrm{O}$ (PDF\#38-0687). So it is easy to deduce that all three polyhedral ZnHCF particles are bound by entirely $\{100\}$ and/or $\{111\}$ facets of the fcc crystal symmetry. The $\mathrm{C}-\mathrm{ZnHCF}$ is bound by $\{111\}$ and $\{100\}$ planes, and the ratio between surface area of $\{111\}$ facets (S111) to that of $\{100\}$ facets (S100) is estimated to be 0.6 . The T-ZnHCF has a higher S111/S100 ratio of ca. 1.2, and the O-ZnHCF particles are almost entirely capped by $\{111\}$ facets.

The morphology of ZnHCF crystals is strongly dependent on the concentration of the reactants. The SEM images of ZnHCF particles synthesized at different concentrations are shown in Fig. S2. At either higher or lower concentrations than $0.01 \mathrm{M}$, irregular particles with no characteristic morphologies were obtained. The concentration of $0.01 \mathrm{M}$ was found to be the optimal condition to obtain uniform ZnHCF particles with regular morphologies. When $\mathrm{ZnSO}_{4}$ and $\mathrm{K}_{3} \mathrm{Fe}(\mathrm{CN})_{6}$ aqueous solutions were quickly poured into the beaker, the orange-red precipitate was obtained immediately, indicating fast nucleation. As seen in the SEM image (Fig. S3), the uniform $\mathrm{ZnHCF}$ crystals were immediately formed in the solution without the process of agitation and age. What's more, the dropping speed of reactants which affects the growth of crystals also plays a crucial role in determining the polyhedral shape of theproducts. The formation mechanism of ZnHCF crystals with controlled morphology is illustrated in Fig. 3, which can be attributed to the homogeneous nucleation and growth of the crystals. Wang's group $^{39}$ has previously observed that the formation of various different shapes of an fcc nanocrystal depended on the ratio $(\mathrm{R})$ of the growth rate along $\langle 100\rangle$ to that along $\langle 111\rangle$, and geometrical shapes of cubooctahedral nanocrystals as a function of the ratio $\mathrm{R}$ were illustrated accordingly. According to Wang's theory, the dropping speed of the reactants may affect the $\mathrm{R}$ values to determine the shape of ZnHCF crystals in this work and the $\mathrm{R}$ values of cuboctahedron, truncated octahedron and octahedron ZnHCF should be $0.87,1.0$ and 1.73, respectively.

Above all, we propose in this paper a simple co-precipation method to prepare shape-controlled $\mathrm{ZnHCF}$ samples. Although someshape-controlled Prussian blue ${ }^{40}$ and its analogues ${ }^{34-37}$ such as $\mathrm{Mn}_{3}\left[\mathrm{Co}(\mathrm{CN})_{6}\right]_{2}, \mathrm{Co}_{3}\left[\mathrm{Co}(\mathrm{CN})_{6}\right]_{2}$ and $\mathrm{Zn}_{3}\left[\mathrm{Co}(\mathrm{CN})_{6}\right]_{2}$ have been previously observed, surfactants or hydrothermal process were required in those reports. In our work, ZnHCF particles with different regular morphologies could be obtained by controlling the concentrations and adjusting the dropping speed of reactants in the absence of surfactants at ambient conditions. Furthermore, this simple reaction procedure can also be applied as a general method to synthesize other PBAs with regular shapes, such as manganese hexcyanoferrate (MnHCF), cobalt hexacyanoferrate (CoHCF) and silver hexacyanofarrate (AgHCF), whose SEM images and XRD diffraction patterns are shown in Fig. S4.

Structure Transformation. As mentioned in some works ${ }^{41,42}, \mathrm{Zn}_{3}\left[\mathrm{Fe}(\mathrm{CN})_{6}\right]_{2} \bullet \mathrm{xH}_{2} \mathrm{O}$ with cubic structure is not stable. The water molecules are very easy to escape by heat treatment, transforming its structure to be rhombohedral, which also occurred in our research. Taking C-ZnHCF as an example, when it was further dried at $70^{\circ} \mathrm{C}$ for 12 hours, the sample was dehydrated and transformed to be rhombohedral structure $\left(\mathrm{Zn}_{3}\left[\mathrm{Fe}(\mathrm{CN})_{6}\right]_{2}\right.$, PDF\#38-0688), as reflected by the XRD pattern shown in Fig. 4. However, the cubooctahedral shape of C-ZnHCF is well preserved after the structural transformation. The same phenomenon was also observed in T-ZnHCF and $\mathrm{O}-\mathrm{ZnHCF}$ when heated at $70^{\circ} \mathrm{C}$ for 12 hours, as shown in Fig. S5. The chemical formula of rhombohedral phase ZnHCF (RZnHCF) with cuboctahedron, truncated octahedron and octahedron shapes was found 


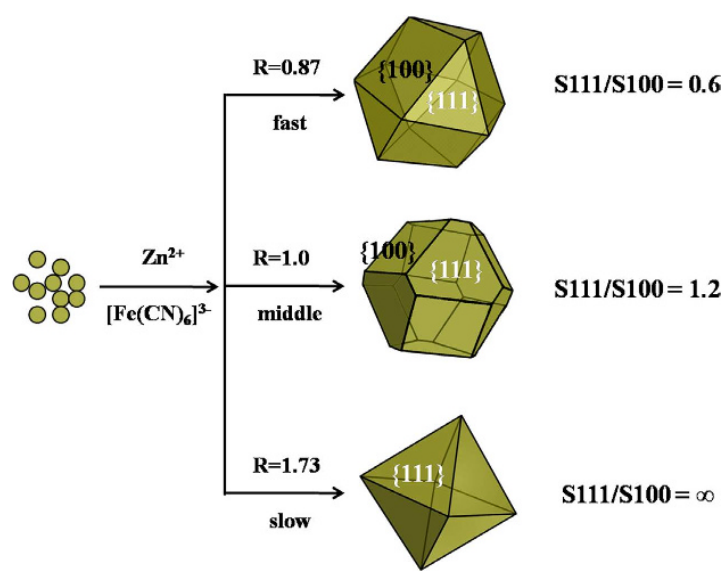

Figure 3. A schematic illustration of nucleation and growth process that determines the shape of $\mathrm{ZnHCF}$ particles obtained with different dropping speed of reactants; the right is the ratio of surface area of facets $\{111\}$ to $\{100\}$.

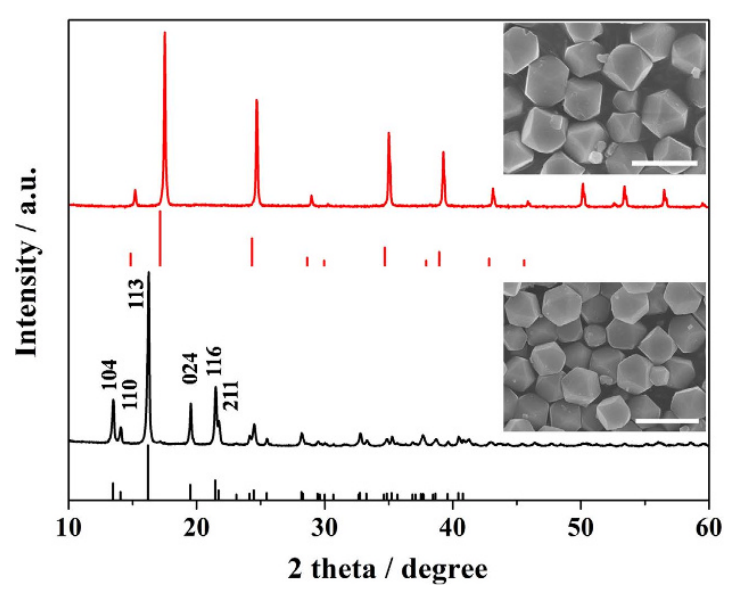

Figure 4. The XRD patterns of cuboctahedron $\mathrm{ZnHCF}$ dried at room temperature with cubic structure(red) and the one (black) further dried at $70^{\circ} \mathrm{C}$ with rhombohedral structure. Insets are the corresponding SEM images of two samples (scar bar $3 \mu \mathrm{m}$ ).

to be $\mathrm{K}_{0.07} \mathrm{Zn}\left[\mathrm{Fe}(\mathrm{CN})_{6}\right]_{0.69}, \mathrm{~K}_{0.08} \mathrm{Zn}\left[\mathrm{Fe}(\mathrm{CN})_{6}\right]_{0.67}$ and $\mathrm{K}_{0.07} \mathrm{Zn}\left[\mathrm{Fe}(\mathrm{CN})_{6}\right]_{0.68}$ respectively, by inductively coupled plasma optical emission spectrometer (ICP-OES). By thermal gravimetric analysis (Fig. S6), the curves of three RZnHCF samples with different shapes were almost overlapped and the mass of water in RZnHCF was negligible. An intriguing effect of shape on the color of RZnHCF powders was found. Irregular RZnHCF is bright yellow, whereas shape-controlled RZnHCFs show green yellow color. Their UV-Vis diffuse reflectance spectra (Fig. S5b) reveals that the cuboctahedron RZnHCF (C-RZnHCF), truncated octahedron RZnHCF (T-RZnHCF) and octahedron RZnHCF (O-RZnHCF) can respectively absorb visible light with a wavelength at $561 \mathrm{~nm}, 559 \mathrm{~nm}$ and $550 \mathrm{~nm}$. For the irregular RZnHCF, the absorption edge is drastically shifted to $588 \mathrm{~nm}$, implying that regular shape may affect the frequency of the stretching mode of the cyano anion in RZnHCF.

To clarify the process of structure transformation from cubic to rhombohedral, it is important to recognize the diversity of the cubic structure of PBAs. The general formula of $\mathrm{PBAs}$ is $\mathrm{A}_{\mathrm{x}} \mathrm{M}\left[\mathrm{P}(\mathrm{CN})_{6}\right]_{\mathrm{y}} \bullet \mathrm{nH}_{2} \mathrm{O}$, in which $\mathrm{A}$ is alkali metals and $\mathrm{M} \& \mathrm{P}$ are transition metals. When the ratio of $\mathrm{M} / \mathrm{P}$ is 1 , there are no vacancies in the cubic structure. If the ratio of $\mathrm{M} / \mathrm{P}$ is not equal to 1 , such as $\mathrm{Fe}_{4}\left[\mathrm{Fe}(\mathrm{CN})_{6}\right]_{3}{ }^{43}$ or $\mathrm{Cu}_{2} \mathrm{Fe}(\mathrm{CN})_{6}{ }^{44}$, the $\left[\mathrm{P}(\mathrm{CN})_{6}\right]^{\mathrm{z}-}$ vacancies will appear in the cubic structure. In the cubic phase $\mathrm{Zn}_{3}\left[\mathrm{Fe}(\mathrm{CN})_{6}\right]_{2} \bullet \mathrm{xH}_{2} \mathrm{O}$ we synthesized, the M/P ratio is $3 / 2$, similar to that of $\mathrm{Cu}_{3}\left[\mathrm{Co}(\mathrm{CN})_{6}\right]_{2}^{45}$, so the $\left[\mathrm{Fe}(\mathrm{CN})_{6}\right]^{3-}$ vacancies are presented as shown in Fig. S7a. According to previous study ${ }^{46}$, only $2 / 3$ of the $\left[\mathrm{Fe}(\mathrm{CN})_{6}\right]^{3-}$ atomic sites are occupied to achieve the electroneutrality with the face-centered cubic framework of $\mathrm{Zn}$ atoms. $1 / 3$ of the $\left[\mathrm{Fe}(\mathrm{CN})_{6}\right]^{3-}$ atomic sites are left as vacancies in the crystal structure, which are nominally occupied by water molecules to pair with the uncoordinated $\mathrm{Zn}$ atoms. The other uncoordinated water molecules are locted in the cages of cubic structure, as seen in Fig. S7b. However, removal of allthese water molecules from cubic phase ZnHCF will lead to the instability of the crystal structure, giving rise to a structural transformation as observed in our experiments. This structural transformation process is illustrated in Fig. 5a, b. Only part of the unit cell is presented in the figures for clarity. After drying of the $\mathrm{Zn}_{3}\left[\mathrm{Fe}(\mathrm{CN})_{6}\right]_{2} \bullet \mathrm{xH}_{2} \mathrm{O}$ 

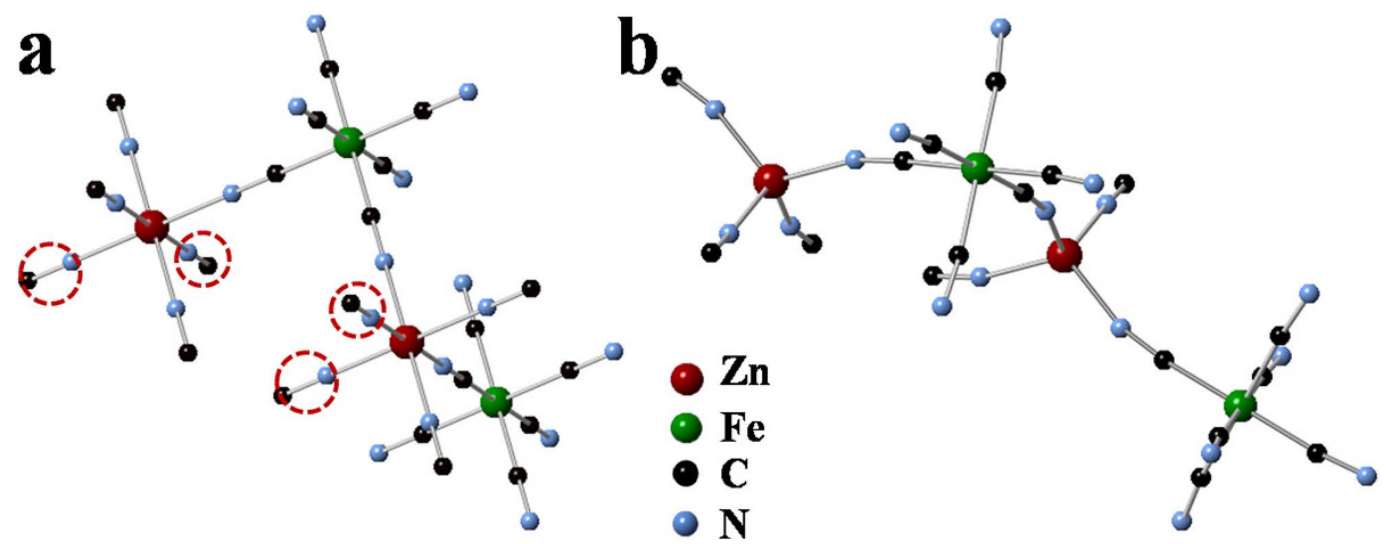

Figure 5. (a) Coordination environments for $\mathrm{Zn}$ and $\mathrm{Fe}$ atoms in cubic structure. The red dashed circles represent $\mathrm{O}$ atoms from water molecules, and the octahedral units, $\left[\mathrm{Fe}(\mathrm{C})_{6}\right] \&\left[\mathrm{ZnN}_{4}(\mathrm{O})_{2}\right]$, behave as rigid blocks. (b) Coordination environments for $\mathrm{Zn}$ and $\mathrm{Fe}$ atoms in rhombohedral phase. The octahedral unit, $\left[\mathrm{Fe}(\mathrm{C})_{6}\right]$, behaves as a practically rigid block. The tetrahedron $\mathrm{ZnN}_{4}$ is slightly distorted.

sample at $70^{\circ} \mathrm{C}$, coordinated water in the crystal is removed, resulting in the transformation of octahedrally coordinated $\mathrm{ZnN}_{4}\left(\mathrm{O}_{2}\right)$ (Fig. 5a) to be tetrahedrally coordinated $\mathrm{ZnN}_{4}$ (Fig. 5b). Thus, the N-Zn-N bond in the dehydrated ZnHCF can no longer sustain its original linearity state in cubic phase ZnHCF, but forms a bond angle of $\sim 108^{\circ}$, typical of tetrahedral coordination. The $\left[\mathrm{Fe}(\mathrm{CN})_{6}\right]$ units, however, still approximately preserve their original geometry. Consequently, the change of the coordination condition of $\mathrm{Zn}$ leads to the transformation from the cubic phase to the rhombohedral phase as shown in Fig. S8. This coordination configuration in RZnHCF results in the formation of large ellipsoidal cavities (Fig. S9), in which the inserted zinc ions can occupy. This structure transformation can be considered as a distortion rather than reconstruction of the internal atoms, therefore the original morphologies of ZnHCF particles which are typical of cubic symmetry are still preserved in RZnHCF samples. Nevertheless, the structural distortion changes the atomic arrangements on the surfaces of the polyhedral particles. For convenience, the orientations of dehydrated RZnHCF crystals are named F111 and F100 to correlate with the $\{111\}$ and $\{100\}$ surfaces on fcc polyhedrons whose morphologies are preserved after structure transformation, while their structures demonstrated in Fig. S10, are totally different from $\{111\}$ and $\{100\}$ crystal planes in cubic ZnHCF.

Morphology Effect on Electrochemical Performance. The electrochemical performance of the dehydrated RZnHCF samples with different shapes was then studied by three-electrode flooded cells. Figure S11 displays the cyclic voltammograms (CVs) of shape-controlled RZnHCF at a scan rate of $2 \mathrm{mV} \mathrm{s}^{-1}$ in $3 \mathrm{M} \mathrm{ZnSO}_{4}$ electrolytes over wide potential ranges, which indicates that the electrochemical reactions are the same accounting for the $\mathrm{Fe}^{2+} / \mathrm{Fe}^{3+}$ redox couple. Figure $6 \mathrm{a}-\mathrm{c}$ present the first discharge capacities of C-RZnHCF, T-RZnHCF and O-RZnHCF, respectively, at various discharge rates from $60 \mathrm{~mA} \mathrm{~g}^{-1}$ to $3000 \mathrm{~mA} \mathrm{~g}^{-1}$. At $60 \mathrm{~mA} \mathrm{~g}^{-1}$ rate C-RZnHCF, T-RZnHCF and O-RZnHCF deliver similar discharge capacities of 69.1, 67.3 and $66.0 \mathrm{mAh} \mathrm{g}^{-1}$, respectively. With the increase of the discharge rate, the difference of the discharge capacity between three samples becomes increasingly apparent. The C-RZnHCF exhibits discharge capacities of 68.9, 67.4, 65.5 and $60.5 \mathrm{mAh} \mathrm{g}^{-1}$ at $300,600,1200$ and $3000 \mathrm{~mA} \mathrm{~g}^{-1}$ rate, respectively, while the corresponding capacities of T-RZnHCF are only 66.4, 60.2, 59.0 and 50.3 $\mathrm{mAh} \mathrm{g}^{-1}$, respectively. The discharge values of O-RZnHCF at higher rates are even lower (51.1, 47.7, 41.3 and $36.0 \mathrm{mAh} \mathrm{g}^{-1}$, respectively). Therefore, C-RZnHCF performs the best rate capability among all three samples, and O-RZnHCFthe worst. Although the O-RZnHCF particles are smaller than T-RZnHCF particles, O-RZnHCF performs worse rate capability than T-RZnHCF, implying that the shape of RZnHCF compounds is more critical for the rate performance than their dimensions. Cycling lives of shape-controlled RZnHCF is also evaluated at $300 \mathrm{~mA} \mathrm{~g}^{-1}$ rate, and the results are shown in Fig. 6d. After 100 cycles, the capacity retention for C-RZnHCF, T-RZnHCF and O-RZnHCF was 93.0\%, 86.6\% and 72.0\%, respectively. Again, C-RZnHCF excels other two samples in the term of cyclic stability.

As all three RZnHCF samples have the same composition and structure, their difference on the electrochemical properties thus is ascribed to their different particle shape. As mentioned above, the particles of C-RZnHCF possess the largest areal proportion of surface F100, T-RZnHCF the second, and O-RZnHCF the smallest (capped all by F111). Comparing with the electrochemical data, it is reasonable to deduce that the charge/discharge performance of RZnHCF is positively correlated with the area of F100. Figure S12 shows the atomic arrangements along the surface oreintations of polyhedral RZnHCF samples. Thus, it is anticipated that F100 surfaces whose orientations are aligned to zinc ions diffusion channels facilitate high discharge rate capabilities, which is confirmed by impedence measurements (Fig. S13). The low frequency region in the electrochemical impedance spectra (EIS, Fig. S13a) corresponds to the zinc-ion diffusion process within the electrodes. Figure S13b shows the relationship between $Z_{\mathrm{re}}$ and $\omega^{-1 / 2}$ in the low frequency region, where $\omega$ is the angular frequecy $(\omega=2 \pi f)$. The low slope indicates good zinc-ion kinetics in the electrode materials. The C-RZnHCF shows the lowest slope among all three samples, suggesting best zinc-ion kinetics. It is anticipated that the less dense atomic arrangements along 
a
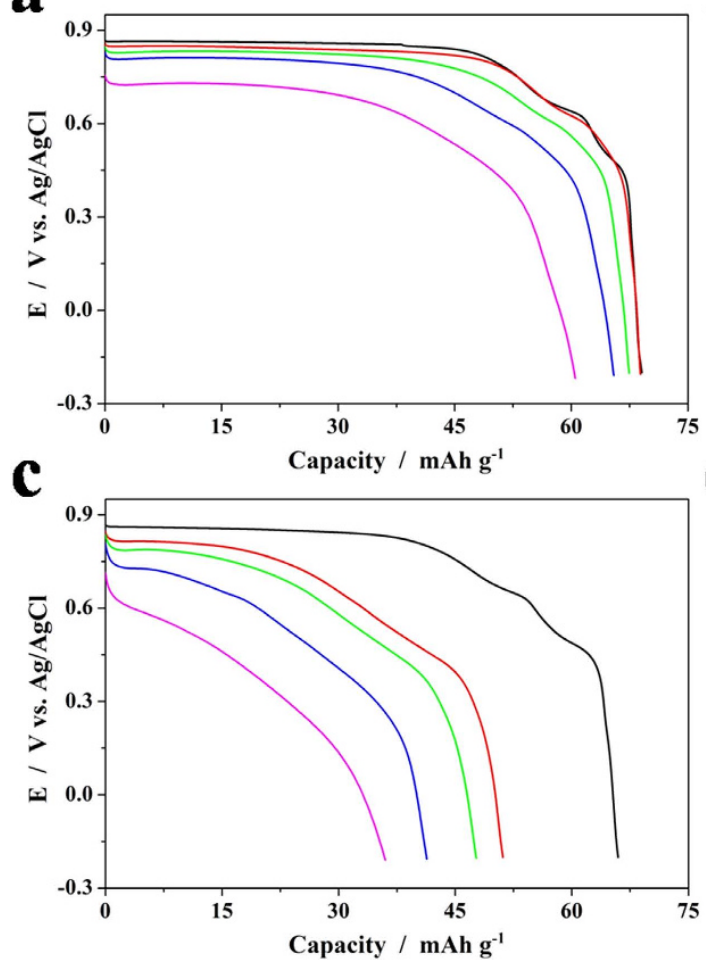

b

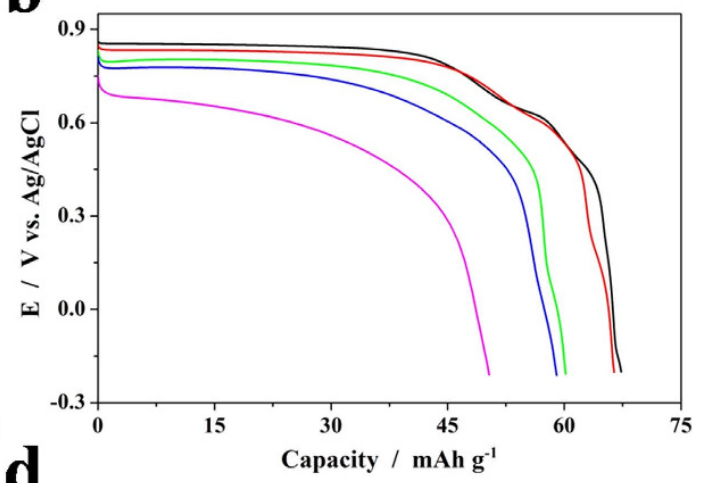

d

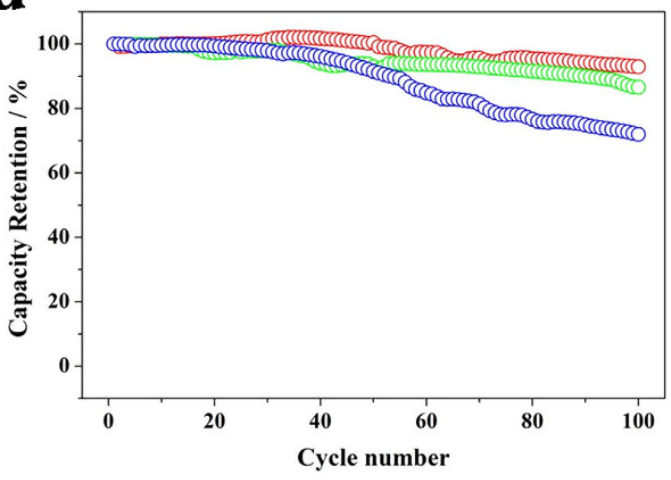

Figure 6. Electrochemical properties of shape-controlled RZnHCFs in $3 \mathrm{M} \mathrm{ZnSO}_{4}$ electrolytes. The discharge curves at the rate of $60 \mathrm{~mA} \mathrm{~g}^{-1}$ (black), $300 \mathrm{~mA} \mathrm{~g}^{-1}$ (red), $600 \mathrm{~mA} \mathrm{~g}^{-1}$ (green), $1200 \mathrm{~mA} \mathrm{~g}^{-1}$ (blue) and $3000 \mathrm{~mA} \mathrm{~g}^{-1}$ (magenta) of (a) C-RZnHCF, (b) T-RZnHCF and (c) O-RZnHCF based on the initial discharge capacity. (d) Cycle life test of shape-controlled RZnHCFs at $300 \mathrm{~mA} \mathrm{~g}^{-1}$. Red, green and blue circles represent C-RZnHCF, T-RZnHCF and O-RZnHCF, respectively.

the F111 directions are more liable to interact with the electrolyte and thus accelerate the sample dissolution. So the C-RZnHCF sample with less F111 orientations in the surface areas will present a better cycling performance. In conclusion, the shape of RZnHCF particles with more surface areas with F100 orientations will be benficial to enhance the electrochemical performance. The similar influence of surface orientations on the ions diffusion and sample dissolution has been observed in other cathode materials ${ }^{33}$.

Zinc-ion Battery Properties. Because of its better electrochemical performance than other two RZnHCF samples, we chose C-RZnHCF as the cathode and zinc as the anode to manufacture the aqueous zinc-ion battery. The typical CV curves of two individual electrodes along with the full cell at a scan rate of $2 \mathrm{mV} \mathrm{s}^{-1}$ are displayed in Fig. 7a. The deposition and dissolution of zinc at anode occurs at around $0 \mathrm{~V}$ vs. $\mathrm{Zn} / \mathrm{Zn}^{2+}$. More details about the structure and morphology evolution during charge/discharge processes and electrochemical properties of zinc anode are exhibited in the supporting information (Fig. S14, S15, S16 and S17). All the evidence confirms that zinc anode is stable during cycling in the zinc-ion battery.Meanwhile, the distinctive reversible redox peaks of cathode appears at ca. $1.77 \mathrm{~V}$ and $1.97 \mathrm{~V}$ vs. $\mathrm{Zn} / \mathrm{Zn}^{2+}$. The full cell exhibits a similar pair of redox peaks as the cathode, appearing at ca. $1.68 \mathrm{~V}$ and $2.00 \mathrm{~V}$ vs. $\mathrm{Zn} / \mathrm{Zn}^{2+}$. The galvanostatic charge and discharge curves of the full cell under a current density of $60 \mathrm{~mA} \mathrm{~g}^{-1}$ between $0.8 \mathrm{~V}$ and $2.0 \mathrm{~V}$ are shown in Fig. $7 \mathrm{~b}$. It delivers a discharge capacity of $66.5 \mathrm{mAh} \mathrm{g}^{-1}$ based on the mass of active cathode materials $\left(60.7 \mathrm{mAh} \mathrm{g}^{-1}\right.$ based on the total mass of active electrode materials). And it has a flat discharge voltage plateau at ca. $1.8 \mathrm{~V}$ with an average operating voltage of ca. $1.73 \mathrm{~V}$, delivering a specific energy density of $105 \mathrm{Wh} \mathrm{kg}^{-1}$ based on the total mass of active electrode materials(see Fig. S18 for details). The discharging voltage profiles at various current densities are displayed in Fig. $7 \mathrm{c}$. Based on the mass of active cathode materials, it delivers the discharge capacities of 66.5, 65.1, 63.2, 59.2, $50.8,42.7$ and $29.3 \mathrm{mAh} \mathrm{g}^{-1}$ at 60,120,180, 300,600, 900 and $1200 \mathrm{~mA} \mathrm{~g}^{-1}$ rate, respectively, showing good rate capability. The discharge capacity retains $80 \%$ of the maximum value after charged and discharged at $300 \mathrm{~mA} \mathrm{~g}^{-1}$ in the $3 \mathrm{M} \mathrm{ZnSO}_{4}$ aqueous electrolyte for 200 cycles (Fig. 7d), indicating that the cell also possesses excellent cyclic stability. After 50 charge-discharge cycles in the $3 \mathrm{M} \mathrm{ZnSO}_{4}$ electrolyte, the XRD pattern of C-RZnHCF electrode keeps the same with the original one (Fig. S19), further suggesting the electrochemical stability of C-RZnHCF.

Reversible Zinc-ion Intercalation. The investigation of the intercalation mechanism for divalent $\mathrm{Zn}^{2+}$ in RZnHCF was conducted in a three-electrode flooded cell with an C-RZnHCF working electrode, a Pt counter electrode and an $\mathrm{Ag} / \mathrm{AgCl}$ reference electrode, and ex situ XRD patterns (Fig. 8a) of the C-RZnHCF electrode at different discharge/charge states of the first cycle in the aqueous $3 \mathrm{M} \mathrm{ZnSO}_{4}$ electrolyte along with corresponding 

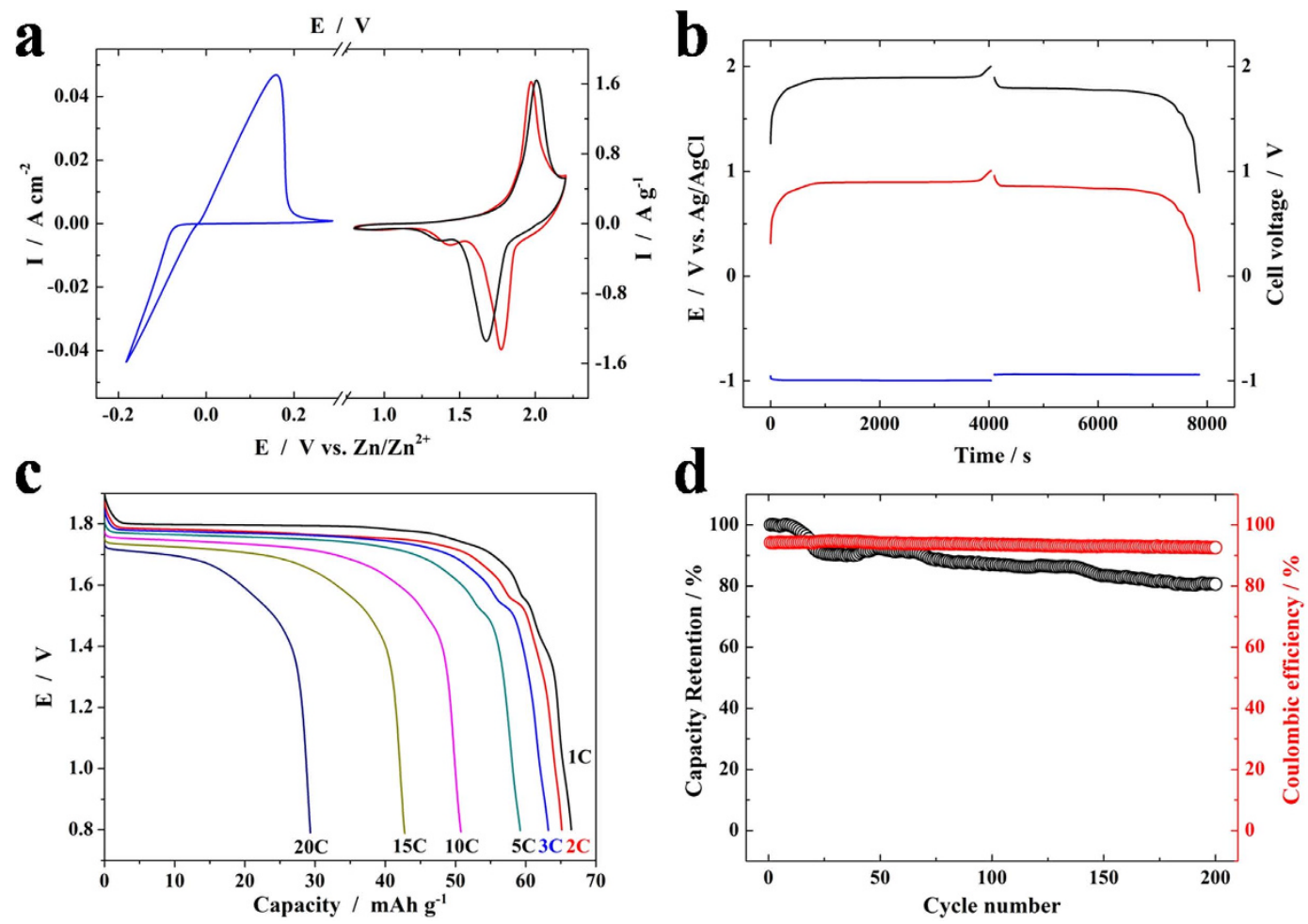

Figure 7. (a) CVs at a scan rate of $2 \mathrm{mV} \mathrm{s}^{-1}$ and (b) GCD profiles at $60 \mathrm{~mA} \mathrm{~g}^{-1}$ for the anode (blue), the cathode (red) and the full cell (black) in $3 \mathrm{M} \mathrm{ZnSO}_{4}$ aqueous electrolytes. (c) Discharge curves of the cell at different rates. (d) Cycle life tests at the current density of $300 \mathrm{~mA} \mathrm{~g}^{-1}$.

discharge/charge curves (Fig. 8b) were measured. Asterisks ${ }^{*}$ ) in Fig. 8a indicates the XRD peaks of the iron grid reference, which is used to calibrate lattice parameters of the same C-RZnHCF sample at different discharge/ charge states. During the $\mathrm{Zn}^{2+}$ insertion process, the position of the strongest XRD peak (113) shifts slightly toward higher angles. The (104) and (110) peaks disappear and one peak near (110) peak appears with discharging. The distinct variation of XRD patterns occurs at the (116) and (211) peaks around 2theta of $22^{\circ}$. During discharging these two peaks split. (116) peak moves to lower angles and (211) peak moves to higher angles. In addition, the intensity of moved (116) peak increases with the insertion of zinc ions. At the end of discharging, its intensity is even higher than the strongest peak (113) of the pristine XRD pattern. During the charging process, the XRD pattern evolves in a reverse way comparing with that in the discharging process, and finally recovers to the original state before discharging, indicating that the structural change along with the insertion/extraction of $\mathrm{Zn}^{2+}$ is highly reversible. Figure S20 displays the ex situ XRD patterns measured in the second cycle, which is the same as those in the first one and further confirms reversible zinc-ion intercalation mechanism.

In Fig. 8c, the value of the unit cell parameter, a, for the C-RZnHCF, determined from the XRD patterns in Fig. 8a, is plotted vs. zinc-ion incorporation, $\mathrm{x}$, in $\mathrm{Zn}_{\mathrm{x}} \mathrm{ZnHCFe}$. ZnHCFe represents the formula of C-RZnHCF, $\mathrm{K}_{0.07} \mathrm{Zn}\left[\mathrm{Fe}(\mathrm{CN})_{6}\right]_{0.69}$, determined by ICP and thermogravimetric analysis. Limited by the number of electrons available from $\mathrm{Fe}^{2+} / \mathrm{Fe}^{3+}$ redox couple, the same absolute charge, i.e., $0.6 \mathrm{Na}^{+}$or $\mathrm{K}^{+}$, or $0.3 \mathrm{Zn}^{2+}$ is stored per formula unit of $\mathrm{ZnHCFe}$. Thus the value of $\mathrm{x}$ can change from 0 to 0.3 . The $\mathrm{C}$ - $\mathrm{RZnHCF}$ possesses a rhombohedral phase with space group of $R-3 \mathrm{ch}$, so the lattice parameter was calculated by Bragg equation and lattice parameter caculation formula of hexagonal system based on (113) and (024) peaks, which always exist during $\mathrm{Zn}^{2+}$ insertion/ extraction. The original XRD pattern was refined by the Rietveld method in Maud software based on two peaks (113) and (024) (Fig. S21) to indentify the lattice parameter, a, which was close to our calculation of the original one, $12.270 \AA$. The lattice parameter monotonically decreases from $12.270 \AA(\mathrm{x}=0)$ to $12.017 \AA(\mathrm{x}=0.16)$ upon insertion of zinc ions and slightly increases to $12.055 \AA$ at $x=0.17$. In the successive discharge process (extraction of zinc ions), the a value then monotonically increases back to $12.261 \AA$ when fully charged, almost the same as that in the original sample, which indicates high reversibility of $\mathrm{Zn}^{2+}$ intercalation in the RZnHCF framework. However, the detailed investigation of structural transformation of RZnHCF during zinc-ion insertion/extraction needs more experimental evidence, which is currently underway in our lab.

\section{Discussion}

To investigate the influence of morphology on the electrochemical performance, we demonstrate a facile and general procedure for preparation of single-crystalline ZnHCF polyhedrons by a simple co-precipitation method without capping agent. However, Three cubic phase ZnHCF samples with cubooctahedral, truncated octahedral or octahedral shapes are obtained at room temperature. Moreover, due to the lost of coordinated water, the structural 

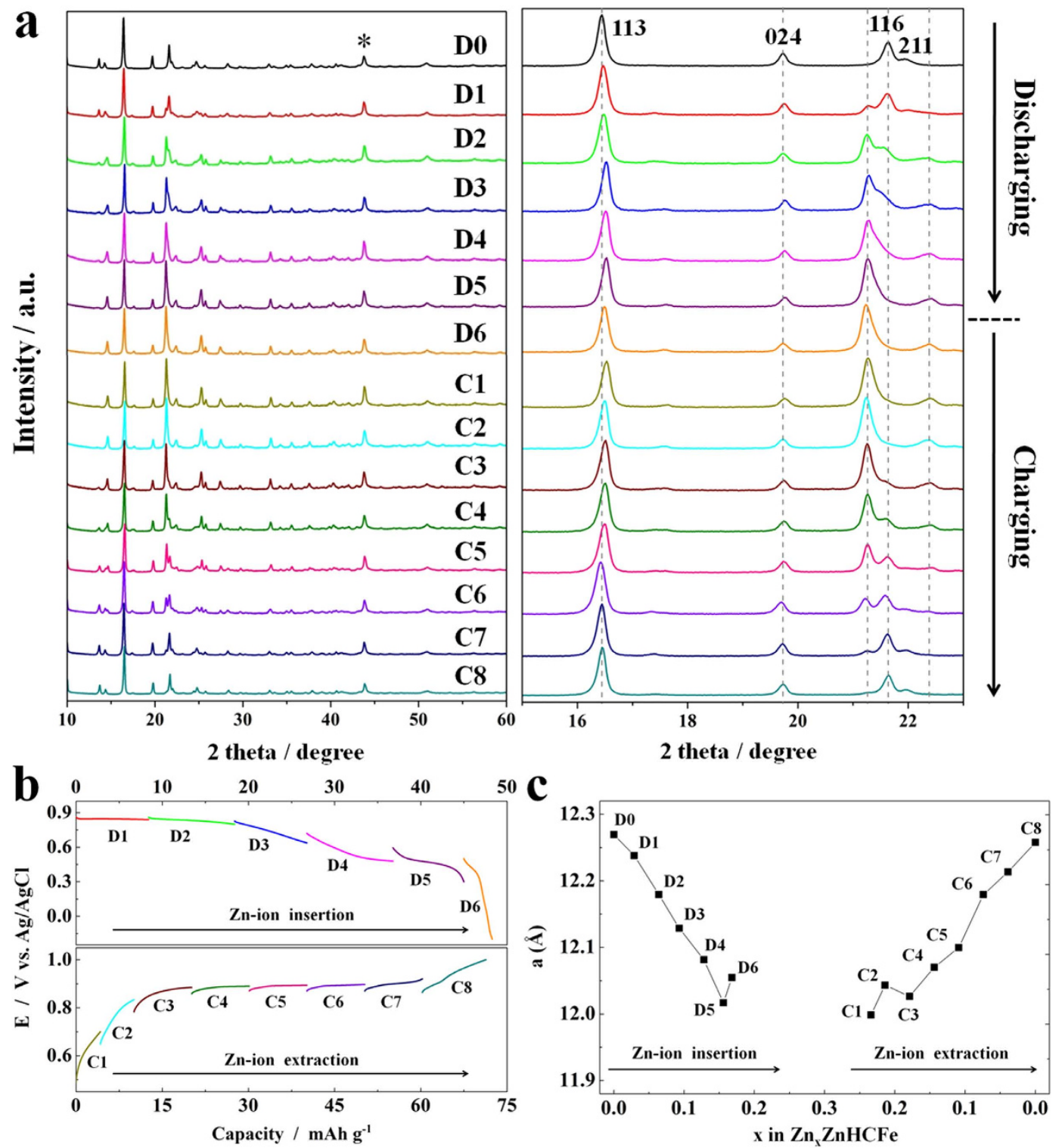

Figure 8. (a) Ex situ XRD patterns of the C-RZnHCF electrode at various discharge and charge states in the first cycle. D0 is the original one before electrochemical measurement. (b) Typical discharge/charge profiles of C-RZnHCF electrodes obtained at corresponding discharge/charge stages captured for ex situ XRD measurement. For example, after the discharge stage of D1, the electrode was characterized by XRD to get the D1 XRD pattern. (c) Changes of the value of lattice parameter (a) during Zn-ion insertion and extraction.

transformation from cubic phase to rhombohedral phase occurs when the ZnHCF samples are dried at elevated temperature, whereas the apparent polyhedral shapes are still well maintained.

Meanwhile, we found that the electrochemical performance of RZnHCF is strongly dependent on their shapes. As a result, RZnHCF with cuboctahedron morphology exhibits better performance in the terms of rate capability and cyclic stability comparing with other two samples, which implies that the diffusion of zinc ions and dissolution of active materials is closely correlative with the structure of surface orientations. While this study is devoted to cathodes based on ZnHCF, a kind of PBAs, with controlled morphology, it seems that the present findings can be further generalized. Therefore, controlling the shape of PBAs with special facets exposed is believed to be an important means to improve their electrochemical performance.

Becuase of the significantly improved performance derived from the fast zinc-ion diffusion and limited dissolution of sample, the C-RZnHCF was chosen as the cathode combined with zinc as the anode to manufacture the aqueous zinc-ion battery in $3 \mathrm{M} \mathrm{ZnSO}_{4}$ electrolytes. Consequently, the battery delivers a high energy density of $104 \mathrm{Wh} \mathrm{kg}^{-1}$ with an average operating voltage of ca. $1.73 \mathrm{~V}$. Finally, ex situ X-ray diffraction techniqueprovides conclusive evidence of the highly reversible zinc-ion intercalation in the rhombohedral framework, which is helpful to understand the intercalation chemistry based on $\mathrm{ZnHCFs}$. 


\begin{abstract}
Methods
Synthesis of Polyhedral ZnHCF. Polyhedral ZnHCF particles were obtained by a simple co-precipitation method at room temperature in the absence of surfactants. Typically, 2 mmol zinc sulfate $\left(\mathrm{ZnSO}_{4} \cdot 7 \mathrm{H}_{2} \mathrm{O}\right.$, Sinopharm Chemical Reagent Co., Ltd, Shanghai, China) was dissolved in $200 \mathrm{ml}$ deionized water to obtain solution $\mathrm{A}$, and $2 \mathrm{mmol}$ potassium ferricyanide $\left(\mathrm{K}_{3} \mathrm{Fe}(\mathrm{CN})_{6}\right.$, Aladdin Industrial Inc, Shanghai, China) was also dissolved in $200 \mathrm{ml}$ deionized water to obtain solution B. Then, solution A and solution B were simultaneously added into an empty beaker under vigorous stirring at room temperature, and the addition time of solution $\mathrm{A}$ and $\mathrm{B}$ was controlled. After stirring for 24 hours at room temperature, the suspensions were left to stand for 12 hours. Then, the obtained solids were filtered, washed with deionized water, and dried at room temperature to obtain cubic $\mathrm{ZnHCF}$. For preparing the cathode electrode, the as-synthesized $\mathrm{ZnHCF}$ solids were further dried at $70^{\circ} \mathrm{C}$ for 12 hours. The shapes of the polyhedral $\mathrm{ZnHCF}$ could be tuned by adjusting the addition time of solution A and B. When solution A and B were poured into the beaker within a total addition time of several seconds, ZnHCF with cuboctahedron shape was obtained. If the reaction solutions were dropped by plastic pipettes within a time span of $\sim 20$ minutes, truncated octahedral ZnHCF particles were prepared. And the octahedron shape particles could be formed by further elongating the addition time to $\sim 2 \mathrm{~h}$, using a peristaltic pump. The synthesis method of irregular ZnHCF has been introduced in our previous work ${ }^{30}$.
\end{abstract}

Synthesis of MnHCF, CoHCF and AgHCF with Regular Shapes. 2 mmol manganese sulfate, cobalt sulfate or silver nitrate $\left(\mathrm{MnSO}_{4} \cdot \mathrm{H}_{2} \mathrm{O}, \mathrm{CoSO}_{4} \bullet 7 \mathrm{H}_{2} \mathrm{O}\right.$ or $\mathrm{AgNO}_{3}$, purchased from Sinopharm Chemical Reagent Co. or Aladdin Industrial Inc, Ltd, Shanghai, China) was dissolved in $200 \mathrm{ml}$ deionized water to obtain solution A, and $2 \mathrm{mmol}$ potassium ferricyanide $\left(\mathrm{K}_{3} \mathrm{Fe}(\mathrm{CN})_{6}\right.$, Aladdin Industrial Inc, Shanghai, China) was also dissolved in $200 \mathrm{ml}$ deionized water to obtain solution B. Then, solution A and B were poured into the beaker under vigorous stirring in several seconds. After agitation and aging for $12 \mathrm{~h}$, the products were filtered and washed by deionized water. Finally, it was dried at $70^{\circ} \mathrm{C}$.

Materials Characterization. Powder X-ray diffraction patterns were performed on an AXS D8 Advance diffractometer ( $\mathrm{Cu} \mathrm{K} \alpha$ radiation, $\lambda=1.5406 \AA$; receiving slit, $0.2 \mathrm{~mm}$; scintillation counter, $40 \mathrm{~mA} ; 40 \mathrm{kV})$ from Bruker Inc. Ex-situ XRD diffraction patterns of cathode electrodes at various charge/discharge states were collected on a Bruker D8 diffractometer operating in Bragg-Brentano geometry with $\mathrm{Cu} \mathrm{K} \alpha$ radiation. The morphology of particles was observed by a Hitachi S-4800 field emission scanning-electron microscope at an accelerating voltage of $8 \mathrm{kV}$. The UV-Vis diffusivereflectancespectra were obtained by Perkin Elmer Lambda 950 spectrometer. Thermal gravimetric analysis was performed on a Pyris Diamond thermogravimetric/differential thermal analyzer (Perkin-Elmer) to analyze the water content in three polyhedral ZnHCFs powders. The K: Zn: Fe ratios of shape-controlled RZnHCFs were determined by inductively coupled plasma optical emission spectrometer (Perkin Elmer Optima 2100 DV). The chemical formulas of C-RZnHCF, T-RZnHCF and O-RZnHCF was found to be $\mathrm{K}_{0.07} \mathrm{Zn}\left[\mathrm{Fe}(\mathrm{CN})_{6}\right]_{0.69}, \mathrm{~K}_{0.08} \mathrm{Zn}\left[\mathrm{Fe}(\mathrm{CN})_{6}\right]_{0.67}$ and $\mathrm{K}_{0.07} \mathrm{Zn}\left[\mathrm{Fe}(\mathrm{CN})_{6}\right]_{0.68}$, respectively.

Electrochemical Measurement. Electrochemical measurements were carried on Solartron 1470E multi-channel potentiostats using either a two-electrode or a three-electrode cell setup. Composite electrodes were cast on steel iron grid. The slurries were prepared by mixing active materials (75 wt\%), Super P (15 wt \%) and polyvinylidene fluoride (10 $\mathrm{wt} \%)$ in $\mathrm{N}$-methyl-2-pyrrolidinone. Finally, electrodes were dried at $80^{\circ} \mathrm{C}$ for $12 \mathrm{~h}$ in air. Discs with diameter of $1.3 \mathrm{~cm}$ were cut for electrochemical tests. Mass loadings for the electrodes were determined by comparing the mass of the electrode with that of the original blank one. Typical electrode active material loading was ca. $8 \mathrm{mg} / \mathrm{cm}^{2}$. The electrode for ex situ X-ray measurement was prepared by extracting the cathode from the three-electrode cell and washing it with de-ionized water and drying at room temperature. For three-electrode setup, an $\mathrm{Ag} / \mathrm{AgCl}$ electrode and Pt gauze were employed as reference and counter electrodes, respectively. For the two-electrode cell, the zinc anode was prepared by mixing $\mathrm{Zn}$ power, activated carbon and polyvinylidene fluoride to obtain the slurry at an appropriate viscosity, which was then coated on current collector, dried at $80^{\circ} \mathrm{C}$, and punched into discs of $1.3 \mathrm{~cm}$ in diameter. $3 \mathrm{M}$ aqueous $\mathrm{ZnSO}_{4}$ solution was used as the electrolytes. The mass ratio of active anode materials to active cathode materials $(9: 100)$ can be referred to our previous work ${ }^{30}$.

\title{
References
}

1. Li, W., Dahn, J. R. \& Wainwright, D. S. Rechargeable Lithium Batteries with Aqueous Electrolytes. Science 264, 1115-1118 (1994).

2. Luo, J.-Y. \& Xia, Y.-Y. Aqueous Lithium-ion Battery $\mathrm{LiTi}_{2}\left(\mathrm{PO}_{4}\right)_{3} / \mathrm{LiMn}_{2} \mathrm{O}_{4}$ with High Power and Energy Densities as well as Superior Cycling Stability. Adv. Funct. Mater. 17, 3877-3884 (2007).

3. Luo, J. Y., Cui, W. J., He, P. \& Xia, Y. Y. Raising the cycling stability of aqueous lithium-ion batteries by eliminating oxygen in the electrolyte. Nat. Chem. 2, 760-765 (2010).

4. Wang, G. J. et al. An Aqueous Rechargeable Lithium Battery with Good Cycling Performance. Angew. Chem. Int. Ed. 46, 299-301 (2007).

5. Qu, Q. T. et al. Porous $\mathrm{LiMn}_{2} \mathrm{O}_{4}$ as cathode material with high power and excellent cycling for aqueous rechargeable lithium batteries. Energy Environ. Sci. 4, 3985-3990 (2011).

6. Li, Z., Young, D., Xiang, K., Caeter, W. C. \& Chiang, Y. M. Towards High Power High Energy Aqueous Sodium-Ion Batteries: The $\mathrm{NaTi}_{2}\left(\mathrm{PO}_{4}\right)_{3} / \mathrm{Na}_{0.44} \mathrm{MnO}_{2}$ System. Adv. Energy. Mater. 3, 290-294 (2013).

7. Whitacre, J. F., Tevar, A. \& Sharma, S. $\mathrm{Na}_{4} \mathrm{Mn}_{9} \mathrm{O}_{18}$ as a positive electrode material for an aqueous electrolyte sodium-ion energy storage device. Electrochem. Commun. 12, 463-466 (2010).

8. Li, Z., Ravnsbak, D. B., Xiang, K. \& Chiang, Y. M. Na $\mathrm{Ti}_{2}\left(\mathrm{PO}_{4}\right)_{3}$ as a sodium-bearing anode for rechargeable aqueous sodium-ion batteries. Electrochem. Commun. 44, 12-15 (2014).

9. Kim, D. J. et al. An Aqueous Sodium Ion Hybrid Battery Incorporating an Organic Compound and a Prussian Blue Derivative. Adv. Energy. Mater. 2014, doi: 10.1002/aenm.201400133.

10. Wu, X. Y. et al. Energetic Aqueous Rechargeable Sodium-Ion Battery Based on $\mathrm{Na}_{2} \mathrm{CuFe}(\mathrm{CN})_{6}-\mathrm{NaTi}_{2}\left(\mathrm{PO}_{4}\right)_{3}$ Intercalation Chemistry. Chem Sus Chem 7, 407-411 (2014). 
11. Pasta, M. et al. Full open-framework batteries for stationary energy storage. Nat. Commun. 5, 3007 (2014).

12. Pasta, M., Wessells, C. D., Huggins, R. A. \& Cui. Y. A high-rate and long cycle life aqueous electrolyte battery for grid-scale energy storage. Nat. Commun. 3, 1149 (2012).

13. Liu, Y. et al. High-performance aqueous sodium-ion batteries with $\mathrm{K}_{0.27} \mathrm{MnO}_{2}$ cathode and their sodium storage mechanism. Nano Energy 5, 97-104 (2014).

14. Tang, W. et al. Aqueous rechargeable lithium batteries as an energy storage system of superfast charging. Energy Environ. Sci. 6, 2093-2104 (2013).

15. Kim, H. et al. Aqueous Rechargeable Li and Na Ion Batteries. Chem. Rev. 114, 11788-11827 (2014)

16. Xu, C. J., Li, B. H., Du, H. D. \& Kang, F. Y. Energetic Zinc Ion Chemistry: The Rechargeable Zinc Ion Battery. Angew. Chem. Int. Ed. 51, 933-935 (2012).

17. Liu, S. et al. P. Aluminum storage behavior of anatase $\mathrm{TiO}_{2}$ nanotube arrays in aqueous solution for aluminum ion batteries. Energy Environ. Sci. 5, 9743-9746 (2012).

18. He, Y. J., Peng, J. F., Chu, W., Li, Y. Z. \& Tong, D. G. Black mesoporous anatase $\mathrm{TiO}_{2}$ nanoleaves: a high capacity and high rate anode for aqueous Al-ion batteries. J. Mater. Chem. A2, 1721-1731 (2014).

19. S, L., Wang, Z. X. \& Chen, L. Q. Prussian Blues as a Cathode Material for Lithium Ion Batteries. Chem. Eur. J. 20, 12559-12562 (2014).

20. Lu, Y. H., Wang, L., Cheng, J. G. \& Goodenough, J. B. Prussian blue: a new framework of electrode materials for sodium batteries. Chem. Commun. 48, 6544-6546 (2012).

21. Wang, L. et al. A Superior Low-Cost Cathode for a Na-Ion Battery. Angew. Chem. Int. Ed. 52, 1964-1967 (2013).

22. Nie, P. et al. Prussian blue analogues: a new class of anode materials for lithium ion batteries. J. Mater. Chem. A2, $5852-5857$ (2014).

23. Lee, H., Kim, Y. I., Park, J. K. \& Choi, J. W. Sodium zinc hexacyanoferrate with a well-defined open framework as a positive electrode for sodium ion batteries. Chem. Comun. 48, 8416-8418 (2012).

24. Wessells, C. D., Peddada, S. V., McDowell, M. T., Huggins, R. A. \& Cui, Y. The Effect of Insertion Species on Nanostructured Open Framework Hexacyanoferrate Battery Electrodes. J. Electrochem. Soc. 159, A98-A103 (2012).

25. Wang, R. Y., Wessells, C. D.; Huggins, R. A. \& Cui, Y. Highly Reversible Open Framework Nanoscale Electrodes for Divalent Ion Batteries. Nano Lett. 13, 5748-5752 (2013).

26. Mizuno, Y. et al. Electrochemical $\mathrm{Mg}^{2+}$ intercalation into a bimetallic CuFe Prussian blue analog in aqueous electrolytes. J. Mater. Chem. A1, 13055-13059 (2013).

27. Li, Z., Xiang, K., Xing, W. T., Carter, W. C. \& Chiang,Y. M. Reversible Aluminum-Ion Intercalation in Prussian Blue Analogs and Demonstration of a High-Power Aluminum-Ion Asymmetric Capacitor. Adv. Energy. Mater. 2014, doi: 10.1002/aenm.201401410.

28. Wessells, C. D., Huggins, R. A. \& Cui,Y. Copper hexacyanoferrate battery electrodes with long cycle life and high power. Nat. Commun. 2, 550 (2011).

29. Wessells, C. D., Peddada, S. V., Huggins, R. A. \& Cui, Y. Nickel Hexacyanoferrate Nanoparticle Electrodes For Aqueous Sodium and Potassium Ion Batteries. Nano. Lett. 11, 5421-5425 (2011).

30. Zhang, L. Y., Chen, L., Zhou, X. F. \& Liu, Z. P. Towards High-voltage Aqueous Metal-ion Batteries Beyond 1.5 V: The Zinc/Zinc hexacyanoferrate System. Adv. Energy. Mater. 2015, doi: 10.1002/aenm.20140930.

31. Wang, L. et al. Crystal Orientation Tuning of $\mathrm{LiFePO}_{4}$ Nanoplates for High Rate Lithium Battery Cathode Materials. Nano. Lett. 12, $5632-5636(2012)$.

32. Choi, D. W. et al. LiMnPO 4 Nanoplate Grown via Solid-State Reaction in Molten Hydrocarbon for Li-Ion Battery Cathode. Nano. Lett. 10, 2799-2805 (2010).

33. Kim, J. S., Kim, K. S., Cho, W., Shin, W. H. \& Kanno, R. A. Truncated Manganese Spinel Cathode for Excellent Power and Lifetime in Lithium-Ion Batteries. Nano. Lett. 12, 6358-6365 (2012).

34. Hu, L., Zhang, P., Chen, Q. W., Yan, N. \& Mei, J. Y. Prussian Blue Analogue $\mathrm{Mn}_{3}\left[\mathrm{Co}(\mathrm{CN})_{6}\right]_{2} \cdot \mathrm{nH}_{2} \mathrm{O}$ porous nanocubes: large-scale synthesis and their $\mathrm{CO}_{2}$ storage properties. Dalton Trans. 40, 5557-5562 (2011).

35. Cao, M. H., Wu, X. L., He, X. Y. \& Hu, C. W. Shape-controlled synthesis of Prussian blue analogue $\mathrm{Co}_{3}\left[\mathrm{Co}(\mathrm{CN})_{6}\right]_{2}$ nanocrystals. Chem. Commun. 17, 2241-2243 (2005).

36. Hu, L., Zhang, P., Chen, Q. W., Mei, J. Y. \& Yan, N. Room-temperature synthesis of Prussian blue analogue $\mathrm{Co}_{3}\left[\mathrm{Co}(\mathrm{CN})_{6}\right]_{2}$ porous nanostructures and their $\mathrm{CO}_{2}$ storage properties. RSC Advances 1, 1574-1578 (2011).

37. Du, D. J., Cao, M. H., He, X. Y., Liu, Y. Y. \& Hu, C. W. Morphology-Controllable Synthesis of Microporous Prussian Blue Analogue $\mathrm{Zn}_{3}\left[\mathrm{Co}(\mathrm{CN})_{6}\right]_{2} \cdot \mathrm{xH}_{2} \mathrm{O}$ Microstructures. Langmuir 25, 7057-7062 (2009).

38. You, Y., Wu, X. L., Yin, Y. X. \& Guo, Y. G. High-quality Prussian blue crystals as superior cathode materials for room-temperature sodium-ion batteries. Energy Environ. Sci. 7, 1643-1647 (2014).

39. Wang, Z. L. Transmission Electron Microscopy of Shape-Controlled Nanocrystals and Their Assemblies. J. Phys. Chem. B104, $1153-1175(2000)$.

40. Wu, X. L., Cao, M. H., Hu, C. W. \& He, X. Y. Sonochemical Synthesis of Prussian Blue Nanocubes from a Single-Source Precursor. Cryst Growth Des. 6, 26-28 (2006).

41. Hernandez, J. R. et al. An atypical coordination in hexacyanometallates: Structure and properties of hexagonal zinc phases. J. Phys. Chem. Sol. 68, 1630-1642 (2007).

42. Balmaseda, J., Reguera, E., Hernandez, J. R., Reguera, L. \& Autie, M. Behavior of transition metals ferricyanides as microporous materials. Microporous Mesoporous Mater. 96, 222-236 (2006).

43. Sharma, V. K. et al. Dynamics of water in prussian blue analogues: Neutron scattering study. J. Appl. Phys. 116, 034909 (2014)

44. Avila, M., Reguera, L., Hernandez, J. R., Balmaseda, J. \& Reguera, E. Porous framework of $\mathrm{T}_{2}\left[\mathrm{Fe}(\mathrm{CN})_{6}\right] \mathrm{xH}_{2} \mathrm{O}$ with T=Co, $\mathrm{Ni}, \mathrm{Cu}$, $\mathrm{Zn}$, and $\mathrm{H}_{2}$ storage. I. Solid State Chem. 181, 2899-2907 (2008).

45. Hartman, M. R., Peterson, V. K. \& Liu, Y. Neutron Diffraction and Neutron Vibrational Spectroscopy Studies of Hydrogen Adsorption in the Prussian Blue Analogue $\mathrm{Cu}_{3}\left[\mathrm{Co}(\mathrm{CN})_{6}\right]_{2}$. Chem. Mater. 18, 3221-3224 (2006).

46. Gravereau, P. \& Garnier, E. Structure de la Phase Cubique de I'Hexacyanoferrate(lll) de Zinc: $\mathrm{Zn}_{3}\left[\mathrm{Fe}(\mathrm{CN})_{6}\right]_{2} \cdot \mathrm{nH}_{2} \mathrm{O}$. ActaCryst. C40, $1306-1309$ (1984)

\section{Acknowledgements}

The authors acknowledgement financial supports from National Natural Science Foundation of China (Grant No. 51404233), Natural Science Foundation of Zhejiang Province (Grant No. LY15B030004), Science Technology Department of Zhejiang Province (Grant No. 2014C31009), Ningbo Natural Science Foundation (Grant No. 2014A610044) and Ningbo Science and Technology Innovation Team (Grant No. 2012B82001).

\section{Author Contributions}

L.Y.Z., X.F.Z. and Z.P.L. designed experiments. L.Y.Z. carried out experiments. L.Y.Z., X.F.Z., Z.P.L. and L.C. contributed data analysis and co-wrote the paper. Z.P.L. and X.F.Z. proposed and supervised the project. All authors reviewed the manuscript. 


\section{Additional Information}

Supplementary information accompanies this paper at http://www.nature.com/srep

Competing financial interests: The authors declare no competing financial interests.

How to cite this article: Zhang, L. et al. Morphology-Dependent Electrochemical Performance of Zinc Hexacyanoferrate Cathode for Zinc-Ion Battery. Sci. Rep. 5, 18263; doi: 10.1038/srep18263 (2015).

(c) (i) This work is licensed under a Creative Commons Attribution 4.0 International License. The images or other third party material in this article are included in the article's Creative Commons license, unless indicated otherwise in the credit line; if the material is not included under the Creative Commons license, users will need to obtain permission from the license holder to reproduce the material. To view a copy of this license, visit http://creativecommons.org/licenses/by/4.0/ 